\title{
(6) OPEN ACCESS \\ Human factors and ergonomics and quality improvement science: integrating approaches for safety in healthcare
}

\author{
Sue Hignett, ${ }^{1}$ Emma Leanne Jones, ${ }^{2}$ Duncan Miller, ${ }^{3}$ Laurie Wolf, ${ }^{4}$ \\ Chetna Modi, ${ }^{5}$ Muhammad Waseem Shahzad, ${ }^{5}$ Peter Buckle, ${ }^{6}$ \\ Jaydip Banerjee, ${ }^{7}$ Ken Catchpole ${ }^{8}$
}

For numbered affiliations see end of article.

\section{Correspondence to Professor Sue Hignett, Loughborough Design School, Loughborough University, Ashby Road Loughborough LE11 3TU, UK: \\ s.m.hignett@|boro.ac.uk}

Received 26 September 2014 Revised 31 January 2015 Accepted 3 February 2015 Published Online First 25 February 2015

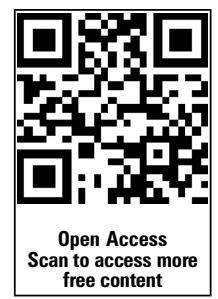

CrossMark

To cite: Hignett $S$, Jones $E L$, Miller $\mathrm{D}$, et al. BMJ Qual Saf 2015;24:250-254.

\section{INTRODUCTION}

In this paper, we will address the important question of how quality improvement science (QIS) and human factors and ergonomics (HFE) can work together to produce safer solutions for healthcare. We suggest that there will be considerable advantages from an integrated approach between the two disciplines and professions which could be achieved in two phases. First, by identifying people trained in HFE and those trained in QIS who understand how to work together and second, by developing opportunities for integrated education and training. To develop this viewpoint we will:

1. Discuss and explore how QIS and HFE could be integrated by building on existing definitions, scope of practice, knowledge, skills, methods, research and expertise in each discipline.

2. Outline opportunities for a longer-term integration through training, and education for healthcare professionals.

\section{HISTORY AND PERSPECTIVES OF QIS AND HFE}

The disciplines and professions of QIS and HFE developed from similar origins in the 20th century to engage workers in the identification of problems and development of solutions. ${ }^{1}{ }^{2}$ They diverged with QIS focussing more on process issues (eg, production quality control) and HFE focussing on wellbeing (occupational health and safety) and performance. Both have been used in healthcare for many years, with several recent papers discussing confusion about jargon in one or both disciplines. ${ }^{3-7}$ We will offer a simple outline of our perspectives for each before suggesting an approach for integrated working.

We are using the term QIS to include both quality improvement and improvement science. ${ }^{8}$ QIS is used, defined and explained in the literature in many different ways, for example, 'the degree to which health services for individuals and populations increase the likelihood of desired health outcomes and are consistent with current professional knowledge'; 'better patient experience and outcomes achieved through changing provider behaviour and organisation through using a systematic change method and strategies" and as "the combined and unceasing efforts of everyone-healthcare professionals, patients and their families, researchers, payers, planners and educators-to make the changes that will lead to better patient outcomes (health), better system performance (care) and better professional development (learning)'. ${ }^{10}$

QIS can include any change which improves quality (patient experience and/ or clinical outcome), a change that uses a generic (eg, training, setting standards) or specific QIS method or approach. ${ }^{11}$ Parry ${ }^{1}$ outlined a history of QIS by drawing on Deming's System of Profound Knowledge and its influence on the development of Improvement Science. Deming's theory included systems thinking, variation (eg, statistical process control), psychology (or social sciences) and the theory of knowledge. ${ }^{12}$ Most QIS practitioners will use a range of improvement methods and tools which may include Plan-Do-Study-Act (PDSA), Model for Improvement, Lean, Six Sigma, Total Quality Improvement and Business Process Reengineering. ${ }^{11}$ 
Human Factors, also known as Ergonomics (we are using these terms interchangeably in this paper), is defined by the International Ergonomics Association $\left(\right.$ IEA) ${ }^{2}$ : 'Ergonomics (or Human Factors) is the scientific discipline concerned with the understanding of interactions among humans and other elements of a system, and the profession that applies theory, principles, data and methods to design in order to optimise human well-being and overall system performance'. The term Ergonomics was used for professional practice in the UK from 1950 (and internationally from 1961), whereas the term Human Factors was used in the USA from 1957. These terms have been harmonised in USA, UK, Australia and New Zealand by the inclusion of both ergonomics and human factors in society, institute and association names; most non-English speaking countries continue to use the term ergonomics. Wilson ${ }^{13}$ suggested that HFE could be regarded as 'one of the first truly multi-, inter-, and cross-disciplinary subjects' by drawing knowledge from design, engineering, psychology, organisational management and human sciences (anatomy, physiology, biomechanics, kinesiology and anthropometry).

\section{WORKING TOGETHER: AN INTEGRATED APPROACH}

In 1990, Deming reflected on his experience as a patient with comments on organisational management problems and the design of medical devices (thermometers), showers, room layout (reach distances) and single rooms. ${ }^{14}$ We suggest that QIS might not have the methods and tools to develop humanistic design solutions, so HFE brings expertise for the design of both medical devices and healthcare facilities as well as system performance. ${ }^{15}$ This change (to eliminate physical, cognitive, system and organisational management problems) might be achieved more successfully through an integrated approach.

Figure 1 proposes an approach for integrated working based on an Institute for Healthcare Improvement (IHI) model for Improvement Science ${ }^{11}$ _but could also have used other QIS and HFE frameworks. When a need for change in healthcare is identified, both QIS and HFE projects can be initiated (Step 1). This could be in response to a patient safety event, but it could also be when a new procedure is to be implemented, or a new piece of equipment introduced, or both. In our opinion, the division of Steps 2 and 3 into defining and exploring, design with stakeholders and methods for implementation offers potential for considerable advances in patient safety. The approaches, methods and tools are mostly different so integrating QIS and HFE will provide a framework to:

- Explore and define a problem by looking at the humans and the rest of the system (HFE and QIS),

- Redesign the tasks, interfaces and system (HFE),
- Define the elements of the intervention and process measures (QIS and HFE),

- Implement the change using expertise in improvement methodology, facilitation and coaching skills, and recognition and reworking of barriers (QIS and HFE).

The combination of QIS and HFE has been described in other studies. ${ }^{3} 16$ In the first, Colligan et $a l^{3}$ compared the use of a process map (QIS) and an hierarchical task analysis (HFE) to explore quality and safety concerns at a community based anticoagulation clinic. They reported that more concerns were identified using the hierarchical task analysis than the sequential diagram. The second example used a combination of QIS and HFE approaches to improve handover from day to night and illustrates both tensions and benefits. ${ }^{16}$ Following baseline observations, a redesign of the process was introduced using a HFE approach. A further adaptation of this was introduced using the PDSA approach, still including most of the HFE-derived intervention. However, a further PDSA and redesign cycle substantially reduced the HFE component of the intervention, and also the measureable efficacy of the process. As HFE uses the understanding of human performance in complex systems to develop interventions and QIS uses the knowledge of complex systems to make changes, the combination of HFE and QIS could be extremely powerful. However, a threat to integrated working was found to be QIS adaptive processes that modified the HFE elements resulting in a deterioration rather than an improvement in human performance. ${ }^{16}$ This threat could be managed by identifying people trained in HFE and those trained in QIS who understand how to work together.

\section{DEVELOPING TRAINING AND EDUCATIONAL OPPORTUNITIES}

As few professionals will have skills (and qualifications) in both QIS and HFE, to achieve benefits from the proposed approach we will need to raise awareness of opportunities for integrated working while also developing opportunities for education and training. With any new approach in healthcare, there needs to be both training (short courses and continuing professional development) and formal educational qualifications to support career pathways. Figure 2 uses a Clinical Leadership Competency Framework from the $\mathrm{UK}^{17}$ to suggest levels of training and education in both QIS and HFE from awareness raising, to student, practitioner and expert practitioner.

For HFE, the student, practitioner and expert levels are aligned to the IEA competency framework. ${ }^{18}$ There are 9 units with detailed elements and performance criteria, for example, Unit 5 outlines knowledge and skills to develop a plan for an HFE design or intervention. The first element (5.1) outlines the scope of an holistic view of HFE in developing 


\begin{tabular}{|c|c|c|}
\hline & QIS & HFE \\
\hline $\begin{array}{l}\text { Step } 2 . \text { What is happening } \\
\text { before the change? }\end{array}$ & $\begin{array}{l}\text { Measure current situation } \\
\text { Define metrics for outcome } \\
\text { (e.g. mortality) and process } \\
\text { (e.g. weekly review/audit) } \\
\text { Methods include: Pareto charts } \\
\text { Ishikawa diagrams, Time Series } \\
\text { Data / Shewhart Nolan's } \\
\text { change ideas } \\
\text { Lean: } 5 S \text { (sort, straighten, shine, } \\
\text { standardize, sustain), } \\
\text { Spaghetti diagrams } \\
\text { Six Sigma: SIPOC (Supplier, } \\
\text { Input, Process, Output, } \\
\text { Customer), } \\
\text { Process mapping; Design of } \\
\text { Experiment, Voice of Customer, } \\
\text { Culture change methods, } \\
\text { Stakeholder assessment, } \\
\text { Statistics and control limits }\end{array}$ & $\begin{array}{l}\text { Understand the change } \\
\text { requirements with respect to } \\
\text { human interactions/behaviour } \\
\text { Task analysis methods for: } \\
\text { 1. System e.g. hierarchical task } \\
\text { analysis } \\
\text { 2. Cognitive decision-making, } \\
\text { situational awareness and } \\
\text { mental models e.g. verbal } \\
\text { protocol analysis, cognitive } \\
\text { work analysis } \\
\text { 3. Physical interactions e.g. link } \\
\text { analysis, postural analysis, } \\
\text { anthropometry }\end{array}$ \\
\hline Step 3. Develop intervention & $\begin{array}{l}\text { Use existing knowledge and } \\
\text { evidence to develop } \\
\text { intervention bundle, } \\
\text { Improvement methods and } \\
\text { tools and Subject Matter } \\
\text { Experts }\end{array}$ & $\begin{array}{l}\text { Design intervention with } \\
\text { stakeholders (Participatory } \\
\text { Ergonomics) } \\
\text { Design Decision Groups } \\
\text { Inclusive (Universal) Design }\end{array}$ \\
\hline
\end{tabular}

Figure 1 Integrating QIS (quality improvement science) and HFE (human factors and ergonomics) professional practice.

solutions to first (performance criteria 5.1a) identify the relative contribution of organisational, social, cognitive, perceptual, environmental, musculoskeletal or industrial factors to the total problem and the second (performance criteria 5.1b) considers the impact of legislation, codes of practice, government and industry-based standards on the problem and possible solutions.

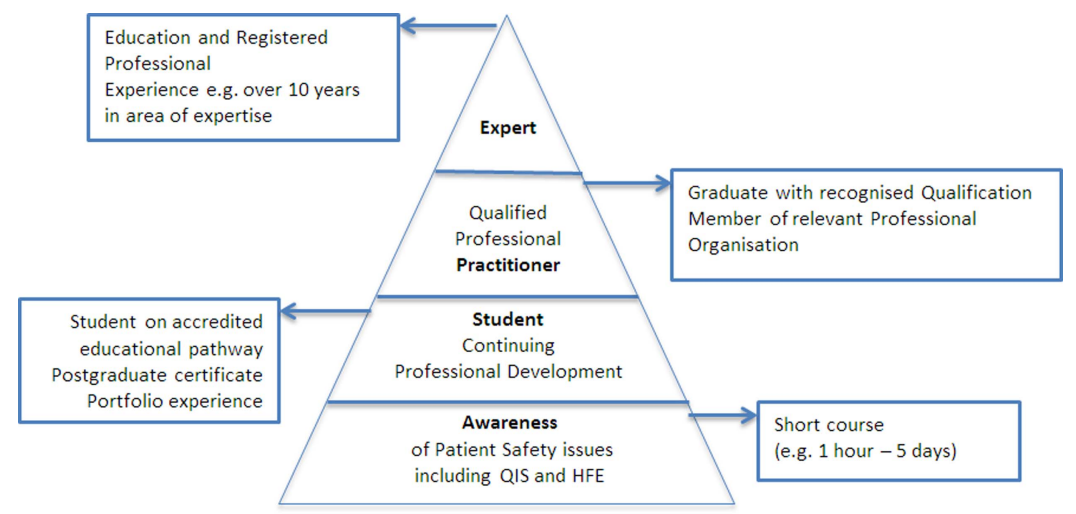

Figure 2 Outline of training and educational opportunities in QIS (quality improvement science) and HFE (human factors and ergonomics) for HCPs (clinical and non-clinical). 
Training and education levels in QIS are defined differently across the world and it has been suggested that some focus more on named methods (eg, PDSA, Six Sigma, Lean, Model for Improvement) and others more on leadership, mentorship and peer review. ${ }^{19}$ Similar to the HFE model, there are defined knowledge areas, for example from the IHI 8 domains to examine healthcare as processes within systems by using diagrams that illustrate flow, inter-relationship and cause-effect, narrative descriptions and case examples. ${ }^{10}$

\section{CONCLUSION}

HFE explores a problem by looking at the people within a system, their interactions with each other and the system and then redesigning the tasks, interfaces and system. It uses a systems analysis approach where humans will be defined as stakeholders within the system. QIS looks at processes within a system to identify variation and then implement change based on testing different approaches to achieve the desired outcome. It involves the people within the system as stakeholders to first change and then sustain the improvement. The processes are mostly delivered by people but the humans are not the focus of the improvement. It uses systems analysis where processes are the components of the system. Both QIS and HFE can provide powerful philosophical and practical approaches to the improvement of healthcare. Both address complexity: HFE by understanding and structuring improvements/interventions based on human capabilities and limitations, and QIS by supporting frontline staff with a theory and method of improvement to identify problems, and then iterate towards local solutions within that complexity.

We believe that there will considerable advantages from a more structured relationship between HFE and QIS as suggested by the National Quality Board (UK) Concordat $^{20}$ 'a wider understanding of human factors [HFE] principles and practices will contribute significantly to improving the quality (effectiveness, experience and safety) of care for patients'. In healthcare, there is a long tradition of multidisciplinary team working and we hope that this culture will promote the integration of QIS and HFE as complementary rather than competing disciplines. We believe that this offers considerable opportunities for increasing safety in healthcare first, by identifying people trained in HFE and those trained in QIS who understand how to work together and second, by developing opportunities for integrated education and training.

\footnotetext{
Author affiliations

${ }^{1}$ Loughborough Design School, Loughborough University, Loughborough, UK

${ }^{2}$ College of Medicine, Biological Sciences and Psychology,

University of Leicester, Leicester, UK

${ }^{3}$ Department of Quality Improvement, Sheffield Teaching

Hospitals NHS Foundation Trust, Sheffield, UK

${ }^{4}$ Department of Operational Excellence, Barnes-Jewish

Hospital, St Louis, Missouri, USA

${ }^{5}$ Health Education East Midlands, Leicester, UK
}

${ }^{6}$ Helen Hamlyn Centre for Design, Royal College of Art, London, UK

${ }^{7}$ Department of Emergency Medicine, Leicester Royal Infirmary, Leicester, UK

${ }^{8}$ Department of Surgery, Cedars-Sinai Medical Centre, Los Angeles, California, USA

Twitter Follow Emma Jones at @emmajonesPhysio

Acknowledgements This has been a challenging viewpoint paper to write and we would like to thank the reviewers for their very helpful and detailed comments. They encouraged us to completely re-think the purpose of the paper from an initial starting point of comparing quality improvement science (QIS) and human factors and ergonomics (HFE) to the much more important question of how to integrate QIS and HFE to improve safety in healthcare.

Contributors The idea for this paper came from SH and DM. LW contributed from her dual qualification in HFE and QIS. ELJ, CM, MWS and JB contributed expert views for QIS and education; $\mathrm{PB}$ and KC contributed HFE perspectives. The paper was written by $\mathrm{SH}$, with contributions from all authors.

\section{Competing interests None.}

Provenance and peer review Not commissioned; externally peer reviewed.

Open Access This is an Open Access article distributed in accordance with the Creative Commons Attribution Non Commercial (CC BY-NC 4.0) license, which permits others to distribute, remix, adapt, build upon this work noncommercially, and license their derivative works on different terms, provided the original work is properly cited and the use is non-commercial. See: http://creativecommons.org/licenses/by$\mathrm{nc} / 4.0 /$

\section{REFERENCES}

1 Parry G. A brief history of quality improvement. J Oncol Pract 2014;10:196-9.

2 Dul J, Bruder R, Buckle P. et al. A strategy for human factors/ ergonomics: developing the discipline and profession. Ergonomics 2012;55:377-95.

3 Colligan L, Anderson JE, Potts HW. et al. Does the process map influence the outcome of quality improvement work? A comparison of a sequential flow diagram and a hierarchical task analysis diagram. BMC Health Serv Res 2010;10:1-9.

4 Russ AL, Fairbanks RJ, Karsh B-T. et al. The science of human factors: separating fact from fiction. BMJ Qual Saf 2013;22:802-8.

5 Catchpole K. Spreading human factors expertise in healthcare: untangling the knots in people and systems. BMJ Qual Saf 2013;22:793-7.

6 Holden RJ, Schubert CJ, Mickelson RS. The patient work system: an analysis of self-care performance barriers among elderly heart failure patients and their informal caregivers. Appl Ergon 2015;47:133-50.

7 Øvretveit J. Does improving quality save money? A review of evidence of which improvements to quality reduce costs to health service providers. The Health Foundation 2009; http:// www.health.org.uk/publications/does-improving-quality-savemoney/ (accessed 6 Dec 2014).

8 Health Foundation. Improvement Science. Research Scan. 2011. http://www.health.org.uk/media_manager/public/75/ Research\%20scan_Improvement\%20science.pdf (accessed 15th Dec 2014).

9 Kohn L, Corrigan JM, Donaldson MS. To err is human. building a safer health system. Washington DC: National Academy Press, 2001. 


\section{Viewpoint}

10 Batalden PB, Davidoff F. What is 'Quality Improvement” and how can it transform healthcare? Qual Saf Health Care 2007;16:2-3.

11 Scoville R, Little K. Comparing lean and quality improvement. IHI White Paper. Cambridge, Massachusetts: Institute for Healthcare Improvement, 2014.

12 Best M, Neuhauser D. W Edwards deming: father of quality management, patient and composer. Qual Saf Health Care $2005 ; 14: 310-12$.

13 Wilson JR. Repositioning ergonomics. Proceedings of the 14th Triennial Congress of the International Ergonomics Association, San Diego, California, USA. July 29-August 4, 2000, Santa Monica: Human Factors \& Ergonomics Society, 6, 190-3.

14 Deming WE. Some notes on management in a hospital. J Soc Health Systems 1990:2. Excerpt reprinted from Deming Interaction, 2006;10:2:2-3.

15 Hignett S, Carayon P, Buckle P, et al. State of science: human factors and ergonomics in healthcare. Ergonomics 2013;56:1491-503.

16 McQuillan A, Carthey J, Catchpole K. et al. Creating a safe, reliable hospital at night handover: a case study in implementation science. BMJ Qual Saf 2014;23:465-73.

17 NHS Leadership Academy. Clinical Leadership Competency Framework. 2011. http://www.leadershipacademy.nhs.uk/wpcontent/uploads/2012/11/NHSLeadership-LeadershipFramework-Clinical-Leadership-Competency-FrameworkCLCF.pdf (accessed 5 Dec 2014).

18 International Ergonomics Association. Professional Standards and Education Committee. Core Competencies in Ergonomics: Units, elements, and performance criteria. 2001. http://iea.cc/ upload/IEAPSE_CoreCompetenciesinErgonomics_fullversion v2_1001.pdf (accessed 6 Dec 2014).

19 Health Foundation. Quality Improvement Training for Healthcare Professionals. 2012. http://www.health.org.uk/ publications/quality-improvement-training-for-healthcareprofessionals/ (accessed 15 Dec 2014).

20 National Quality Board. Human Factors in Healthcare: a Concordat from the National Quality Board. 2013. http:// www.england.nhs.uk/wp-content/uploads/2013/11/nqb-humfact-concord.pdf (accessed 25 Aug 2014). 